\title{
ANÁLISE MULTICRITÉRIO PARA DETERMINAÇÃO DO ISOLAMENTO GEOGRÁFICO E DESENVOLVIMENTO EM ILHAS ESTUARINAS DO MUNICÍPIO DE BELÉM-PA
}

\author{
Arley Martins Quaresma \\ Universidade Federal do Pará, Belém, PA, Brasil \\ arleymartins20@gmail.com \\ Claudio Fabian Szlafsztein \\ Núcleo de Altos Estudos Amazônico, UFPA. Belém, PA, Brasil \\ ioselesz@gmail.com
}

\begin{abstract}
RESUMO
Os fluxos de desenvolvimento socioeconômico das ilhas amazônicas são fortemente relacionados por sua relevância, singularidade, e valor em relação aos caminhos de desenvolvimento dos centros urbanos. A distância física das ilhas do município de Belém-PA determina as unidades insulares a níveis de desenvolvimento territorial distintos. Este artigo propõe uma análise a partir de critérios pré-estabelecidos a fim de determinar o grau de isolamento e a relação de desenvolvimento das ilhas mais relevantes do município de BelémPA. A metodologia para determinação do grau de isolamento levou em consideração dois indicadores: Acessibilidade e conectividade e suas respectivas variáveis. Contudo, o artigo examinará como o distanciamento físico do continente afeta a capacidade de uma ilha determinar seu próprio destino e curso de desenvolvimento. A parti dos resultados constatouse que as ilhas mais isoladas se sustentam de diferentes condições de autonomia e desenvolvimento. As ilhas com menor grau de isolamento possuem ligações físicas e conectividade intensa, maneira pela qual reduzem o isolamento. Em tais ligações, as ilhas mais propensas ao desenvolvimento não são as mais próximas ao continente, mas as que possuem maiores ofertas de serviços aos ilhéus.
\end{abstract}

Palavras-chave: Ilhas. Isolamento geográfico. Desenvolvimento insular. Zona costeira amazônica. Belém-PA

\section{MULTICRITERY ANALYSIS FOR DETERMINATION OF GEOGRAPHICAL ISOLATION AND DEVELOPMENT IN ISLANDS IN THE MUNICIPALITY OF BELÉM-PA}

\begin{abstract}
The development flows of the Amazonian islands are strongly related by their relevance, uniqueness, and value in relation to the development paths of urban centers. The physical distance of the islands of the municipality of Belém-PA determines the island units at different levels of development. This article proposes an analysis based on pre-established criteria in order to determine the degree of isolation and the development relationship of the most relevant islands in the municipality of Belém-PA. The methodology for determining the degree of isolation will take into account two indicators: Accessibility and connectivity and their respective variables. However, the article will examine how physical distance from the continent affects an island's ability to determine its own destiny and course of development. Based on the results, it was found that the most isolated islands have been fed different conditions of autonomy and development. Islands with a lower degree of isolation have physical connections and intense connectivity, a way in which they reduce isolation. In such connections, the islands most prone to development are not those closest to the continent, but those with the greatest service offerings to the islanders..
\end{abstract}

Keywords: Islands. Geographic isolation. Island development. Amazonian coastal zone. Belém-PA. 


\section{INTRODUÇÃO}

A zona costeira amazônica é definida a partir do Plano Nacional de Gerenciamento Costeiro - Lei $7661 / 1988$ que estabelecem os limites e os municípios constituintes das zonas costeiras do Brasil. O Programa de Gerenciamento da Zona Costeira do estado do Pará (GERCO/PA), de responsabilidade da Secretaria Estadual do Meio Ambiente e Sustentabilidade, instituído pela Lei Estadual n 5587/1995.

O setor insular do município de Belém (capital do Estado do Pará) está composto por 42 ilhas (333 $\mathrm{km}^{2}$ ), onde as ilhas principais são agrupadas nas regiões Noroeste (Onças, Cotijuba, Jutuba, Paquetá), Norte (Caratateua/Outeiro e Mosqueiro) e Sul (Combú e Murutucu) (CODEM, 2012).

A cidade de Belém representa um centro de poder econômico e político, polarizando as ilhas do seu entorno, com destaque para as ilhas de Mosqueiro, Caratateua-Outeiro, Cotijuba e Combu. Contudo, as ilhas do município de Belém se caracterizam principalmente como fontes de parte de suprimento de alimentos e de materiais destinados à construção civil, extrativismo, agricultura, assim como o turismo (CABRAL et al., 2015). Ne entanto, muitas regiões insulares são caracterizadas por condições de isolamento definidas por barreiras físicas, como porção de terra desvinculada do continente rodeada por água, outras vezes delineada por barreiras intangíveis, ou seja, o isolamento ligado as formas de acesso que as regiões insulares estão submissas (GRYDEHOJ, 2019). Nesse sentido, as questões de isolamento poderão estar ligadas ao contexto geográfico, mas também a todas as barreiras que limite o acesso.

Quando se abordam estudos relacionados a ilhas, a inacessibilidade e o isolamento estão diretamente correlacionados com o desenvolvimento (BALDACCHINO, 2019; GRYDEHOJ, 2019; HUDSON e DOOGAN, 2019;). Assim sendo, o desenvolvimento é caracterizado como um termo amplo, mas pode ser visto como um esforço geral para reduzir disparidades (emprego e geração de riqueza) e atividades econômicas em regiões, portanto, é um processo em que as pessoas são ao mesmo tempo atores e beneficiários (MELÉNDEZ e GONZÁLEZ, 2016; PIKE et al., 2017).

Desse modo, o grau de isolamento em ilhas associa-se ao nível de desenvolvimento, onde cada ilha se configura de forma diferenciada, mesmo localizadas próximas ou distantes do continente. As ilhas estão isoladas geograficamente por um limite natural constituído pela água ao seu redor, onde desta forma, devido à distância do continente se estabelecem fluxos de conectividade que ocorrem de maneira particular em cada ilha devido ao seu relativo isolamento (PUGH, 2018).

A construção de uma ligação fixa (ponte) a partir do continente para a ilha (dependendo da distância) minimiza a autonomia da ilha, e se propõem a uma dependência do continente (GRYDEHOJ, 2019). Quanto maior o tamanho e a população da ilha o grau de dependência do continente será menor, o que corresponde onde há maior concentração populacional maiores serão as possibilidades de políticas públicas serem implantadas (BALDACCHINO, 2019).

A distância física do continente para as ilhas resulta em um e isolamento natural, essa distância varia de maior ou menor proporção. Nesse sentido, o isolamento físico surge como fator de dependência ou autonomia. Para algumas ilhas, o isolamento resulta em uma maior autonomia de desenvolvimento, entretanto, para outras ilhas o isolamento físico se torna uma barreira para o desenvolvimento. Contudo, a especificidade de cada ilha resulta em uma maior ou menor dependência/autonomia.

A autonomia na gestão insular se refere ao poder de administrar o seu território e criação de formas para o desenvolvimento insular, com mínima interferência exterior. Contudo, quando essa autonomia é inexistente, as ilhas ficam sujeitas a dependência externa, o que leva a redução no seu desenvolvimento (GRYDEHOJ et al., 2015). A dependência insular é definida como uma dependência econômica e política de cidades ou distritos próximos geograficamente, que podem ser expressos particularmente em pequenas ilhas ou ilhas periféricas (CHAPERON e BRAMWELL, 2013).

Exemplos da relação do isolamento e desenvolvimento (Figura 1): 
Figura 1 - A relação do isolamento e desenvolvimento insular.

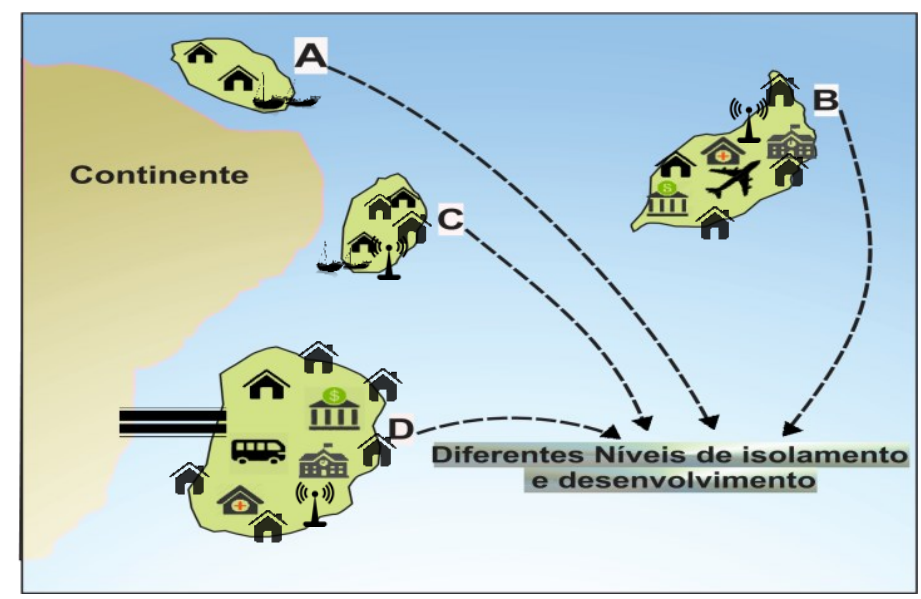

Fonte: Elaborado pelo autor.

A ilha $\mathrm{A}$ apesar de próxima ao continente, não possui ponte de ligação para o continente e nem serviços básicos. A extensão territorial e o contingente populacional são reduzidos. As formas de romper o isolamento dependem exclusivamente do transporte fluvial. Tais características definem a ilha em uma região insular de baixo desenvolvimento e alto grau de isolamento, o que resulta em uma dependência extrema do continente

A ilha $B$, a mais distante geograficamente do continente, porém apresenta uma forte presença de serviços básicos e avançados como transporte aéreo. Sua extensão territorial possibilitou a presença de um maior contingente populacional em relação a ilha A. A ilha B exclusivamente por dispor de uma grande presença de serviços e transporte aéreo, consegue diminuir demasiadamente 0 isolamento geográfico, resultando um baixo isolamento relacionando a um eficaz desenvolvimento.

A ilha $\mathrm{C}$, bem como a ilha $\mathrm{A}$, está próxima geograficamente do continente, porém há uma mínima presença de serviços básicos. Possui a menor extensão territorial entre as ilhas, e um de contingente populacional maior que a ilha $A$. A ilha $C$ dispõe de um serviço de telefonia e linha de embarcações, maneira pela qual se utiliza para diminuir o isolamento geográfico. Nesse sentido, a ilha $C$ apresenta um baixo o desenvolvimento, pois mesmo com a presença de telefonia e rede de transporte fluvial ainda depende de outros serviços do continente.

A ilha $D$, é a única ilha que possui uma ligação com continente via eixo rodoviário através de pontes. Essa ligação física possibilita uma maior presença de serviços básicos e uma rede de transporte rodoviário regular. A ilha $D$, dentre as demais é a maior ilha em extensão territorial e contingente populacional. Desse modo, a ilha $\mathrm{D}$ apresenta um médio grau de isolamento e desenvolvimento, pois se comparar como a ilha $B$ em que a presença de serviços é maior e transporte é mais eficaz, a ilha $D$ se encontra numa faixa intermediária de condição de isolamento.

Os trabalhos referentes ao grau de isolamento geográfico em ilhas e estudos relacionados ao desenvolvimento e condições de isolamento têm uma importância significativa quando se refere a dinâmica insular em outros países (CARVAJAL et al., 2012; BETZOLD, 2015; GRYDEHOJ e CASAGRANDE, 2020; HUDSON e DOOGAN, 2019; ZAMORANO e SZLAFSZTEIN, 2020). Desse modo, a possibilidade de verificar tais temas em ilhas no contexto amazônico é relevante para o universo dos estudos insulares e uma contribuição para região insular paraense.

Nesse sentido, procura-se responder a qual é o contexto que as ilhas assumem no município de Belém e quais as condições de isolamento geográfico e a perspectivas de desenvolvimento estão inseridas? A problemática também implica no nível de dependência do continente e autonomia de autogestão. Nesse sentido, o presente artigo tem como objetivo analisar o grau de isolamento geográfico e o desenvolvimento das ilhas de Mosqueiro, Caratateua-Outeiro, Cotijuba e Combú no município de Belém. 


\section{CARACTERIZAÇÃO DA ÁREA DE ESTUDO}

A cidade de Belém localiza-se na bacia hidrográfica do rio Tocantins, cujo ambiente fluvial é formado na confluência dos rios Pará, Acará e Guamá (Figura 2). O município de Belém, é composto por uma região continental e a outra insular, $65 \%$ do seu território corresponde a região insular compreendida em 42 ilhas (CODEM, 2012) (Tabela 1).

Tabela 1 - Ilhas do Município de Belém, com destaque para as ilhas de maiores áreas territoriais

\begin{tabular}{|c|c|c|c|}
\hline Ilhas & Área (km2) & Ilhas & Área $(\mathrm{km} 2)$ \\
\hline Ilha de Mosqueiro & 211,7923 & Ilha Murutucu & 8,6616 \\
\hline Ilha de São Pedro & 4,1103 & $\begin{array}{l}\text { Ilha de Paquetá ou } \\
\text { Ururubuóca }\end{array}$ & 7,8202 \\
\hline Ilha de Cunuarii & 2,4747 & Ilha do Cintra & 6,4659 \\
\hline Ilha do Papagaio & 0,8252 & Ilha de Jutuba & 5,0463 \\
\hline Ilha da Conceição & 0,3327 & Ilha dos Papagaios & 3,5158 \\
\hline Ilha do Maruim II & 0,0278 & Ilha Nova & 2,6892 \\
\hline Ilha SD1 & 0,0247 & Ilha Jararaquinha & 1,8804 \\
\hline Ilha SD2 & 0,0200 & Ilha Longa & 1,0539 \\
\hline Ilha Maruim I & 0,0196 & Ilha da Barra & 1,0049 \\
\hline Ilha das Pombas & 0,0148 & Ilha dos Patos & 0,1262 \\
\hline Ilha SD3 & 0,0130 & Ilha do Meio & 0,1137 \\
\hline Ilha do Maracujá & 0,0068 & Ilha Coroinha & 0,1067 \\
\hline Ilha SD4 & 0,0029 & Ilha Negra I & 0,0967 \\
\hline Ilha SD7 & 0,0027 & Ilhinha & 0,0905 \\
\hline Ilha SD5 & 0,0024 & Ilha Santa Cruz & 0,0685 \\
\hline Ilha SD6 & 0,0022 & Ilha Tatuoca & 0,0631 \\
\hline Ilha dos Amores & 0,0011 & Ilha Negra II & 0,0253 \\
\hline Ilha de Caratateua/Outeiro & 31,4491 & Ilha SD8 & 0,0028 \\
\hline Ilha de Cotijuba & 15,8071 & Ilha do Cruzador I & 0,0009 \\
\hline Ilha do Combu & 14,9360 & Ilha do Cruzador II & 0,0008 \\
\hline Ilha Paulo da Cunha & 9,2365 & Ilha do Cruzador III & 0,0004 \\
\hline
\end{tabular}

Km2: Quilômetros quadrados

Fonte: Companhia de desenvolvimento e administração da área metropolitana de Belém - CODEM, 2012.

O recorte de estudo são as ilhas de Mosqueiro, Caratateua-Outeiro, Cotijuba e Combu, no qual possuem maiores em área territorial e mais habitadas, o que resulta em maiores relações com a sede municipal (CODEM, 2012). As ilhas de Caratateua-Outeiro, Cotijuba e Combu pertencem ao distrito administrativo de Outeiro-DAOUT e a ilha de Mosqueiro ao distrito administrativo de MosqueiroDAMOS (Figura 2). 
Figura 2 - Área de estudo e localização das ilhas do município de Belém-PA.

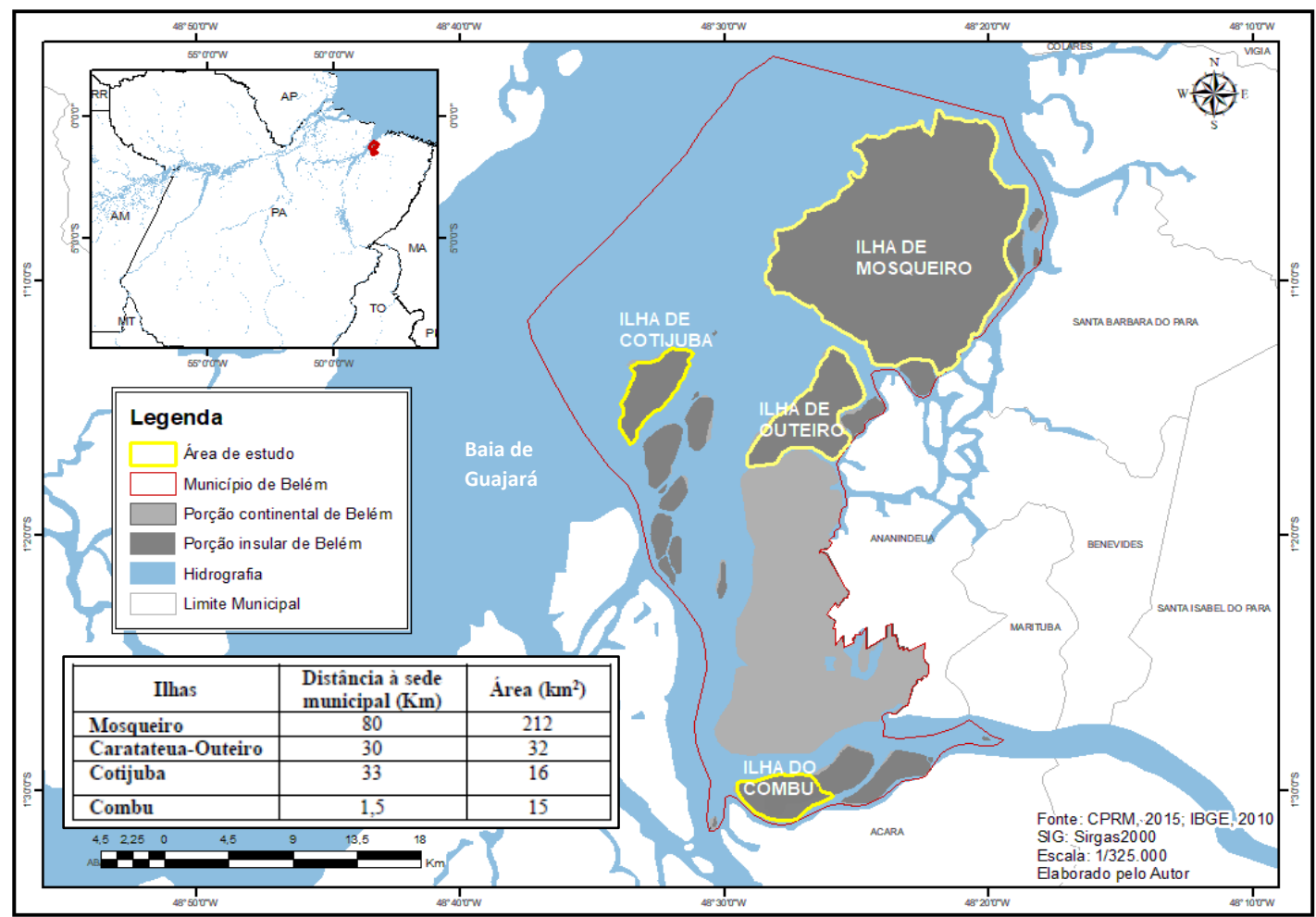

Fonte dos dados CPRM - linhas de costas e ilhas, 2015 e IBGE - base territoriais, 2010.

As ilhas que compõem o município de Belém só passaram a ter atenção sistemática do poder público a partir da década de 1970, por motivos de reivindicação da população como a melhoria de transporte, a construção de escolas e postos de saúde. A partir destas exigências, implementou-se pontes da sede municipal para as ilhas de Mosqueiro e Outeiro com a finalidade de facilitar o acesso, o que promoveu a valorização das propriedades nas ilhas, crescimento populacional desordenado, impactos ambientais, e a especulação imobiliária (MIRANDA, 2015).

As ilhas de Mosqueiro e Caratateua-Outeiro apresentam maiores índices populacionais se comparado com as ilhas de Cotijuba e Combu (Gráfico, 1), a conexão por pontes possibilitou expansão urbana da cidade de Belém para as ilhas, onde se tornaram regiões insulares com dados populacionais expressivos (IBGE, 2010).

Gráfico1 - Dados populacionais da llhas de 2010 e 2019

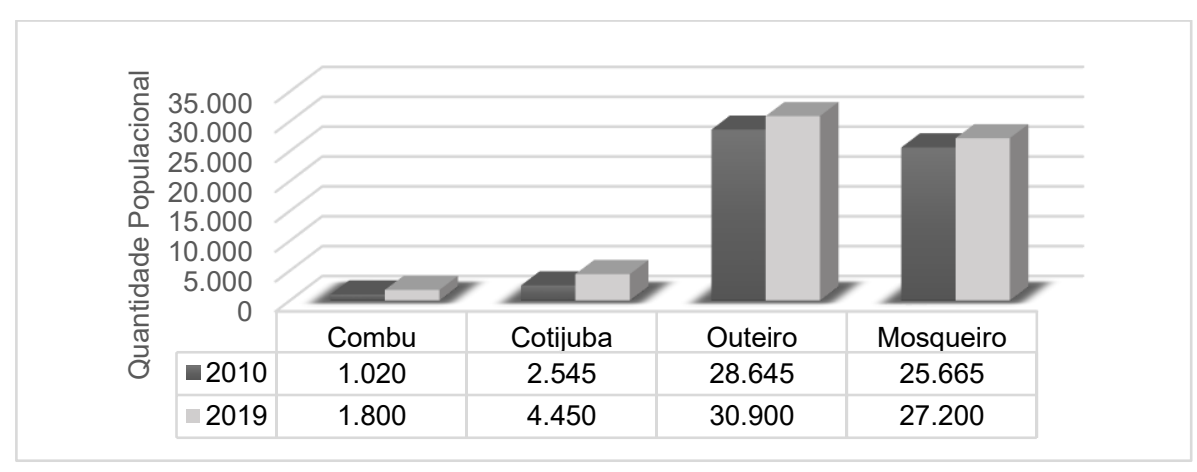

Fonte: IBGE - Censo demográfico 2010 e estimativas populacionais 2019 
As ilhas de Cotijuba e Combu possuem menor contingente populacional se comparar com as outras ilhas analisadas, onde apresentam uma dinâmica insular distinta das demais, cuja o fato da autonomia ser maior que em ilhas que possuem pontes. Contudo, apesar das ilhas apresentarem características populacionais distintas, elas enfrentam problemas em comum, como falta de infraestrutura de saneamento básico, abastecimento de água potável e energia elétrica, além da precariedade no atendimento de políticas de saúde e de educação (BRAZÃO e SILVA, 2010; CABRAL et al., 2015; NUNES, 2016; VIANA, 2017).

\section{METODOLOGIA}

O processo metodológico da análise multicritério consiste em estruturar e combinar diferentes indicadores e variáveis no processo da pesquisa. A base das opções de escolha múltiplas e o tratamento dado a cada uma das escolhas condiciona em grande medida a decisão do estudo. Nesse sentido, analisar um grupo de alternativas sobre múltiplos critérios para resolver um determinado problema (GOMES et al., 2011) (Figura 3).

Figura 3 - Etapas da análise multicritério.

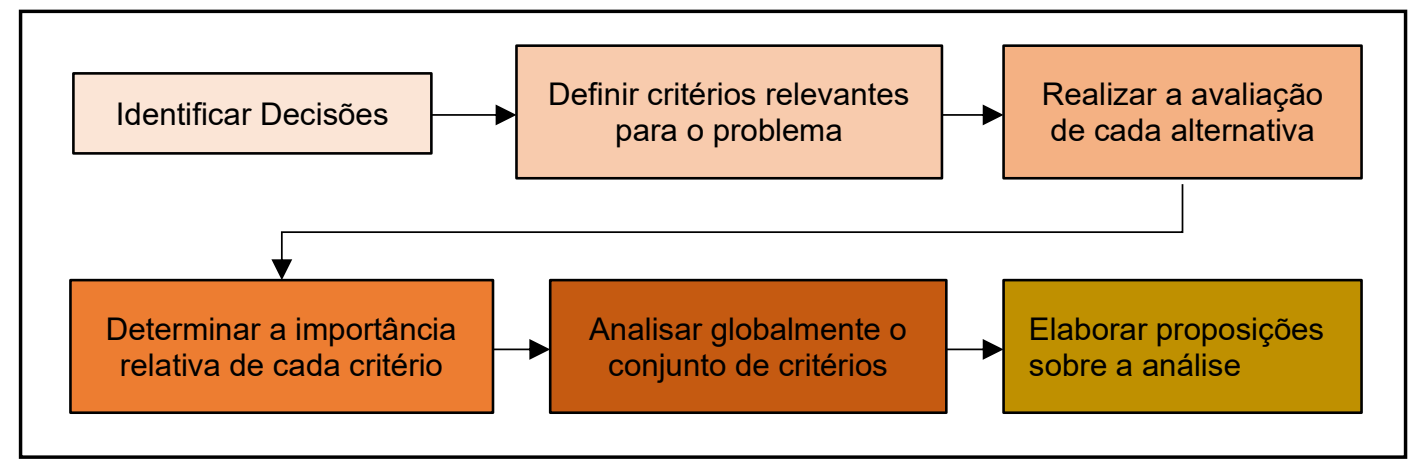

Fonte: Adaptado de Gomes et al., 2011.

A identificação de decisão é necessária definir claramente as regras de trabalho a serem utilizadas. Nesse sentido, busca-se obter elementos que respondam a questões levantadas e elementos ajudam a explicar a decisão. A realização de avaliação de cada alternativa determina a importância de cada critério estipulado. Os dados combinados mostram o resultado final, o que isolados não obtém o resultado esperado. Nesse sentido, esta técnica permite que a decisão seja pautada com base nos critérios considerados relevantes para o problema em questão, em que a importância dos critérios é definida por estes em um processo interativo.

Nesse sentido, a análise multicritério em ilhas teve como referência a metodologia adaptada do grau de isolamento de Carvajal et al., (2012) e Zamorano e Szlafsztein (2020), e tem como base o uso de dois indicadores, a acessibilidade e conectividade de cada ilha (Quadro 1) e cinco variáveis:

Os Indicadores quantificados através da seguinte fórmula (adaptado de Carvajal, 2012; ZAMORANO e SZLAFSZTEIN, 2020):

\section{ÍNDICE GRAU DE ISOLAMENTO = ACESSIBILIDADE + CONECTIVIDADE $/ 2$}

O índice "Grau de Isolamento" se baseia no quesito inversamente proporcional, onde o resultado da acessibilidade e conectividade quando for maior, menor será o grau de isolamento, e quando menor, maior será o grau de isolamento. Como destacado abaixo.

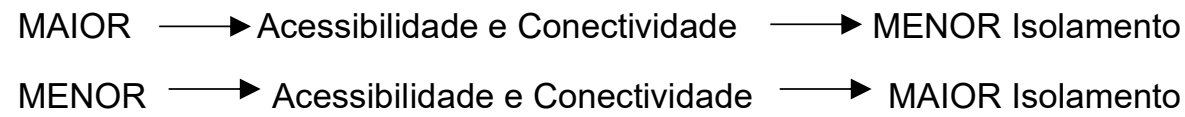

A definição dos indicadores como parâmetro de isolamento, levou em consideração as características de todo tipo de acesso, tanto físico como por telecomunicações, especialmente depois do aumento dos dispositivos móveis e a disseminação da internet possibilitando uma conexão virtual. 
Quadro 1 - Indicadores para identificação do grau de isolamento e suas variáveis

\begin{tabular}{|c|c|c|c|c|c|}
\hline Indicadores & Definição & Fonte & Variáveis & Valor & Fonte \\
\hline \multirow{7}{*}{ 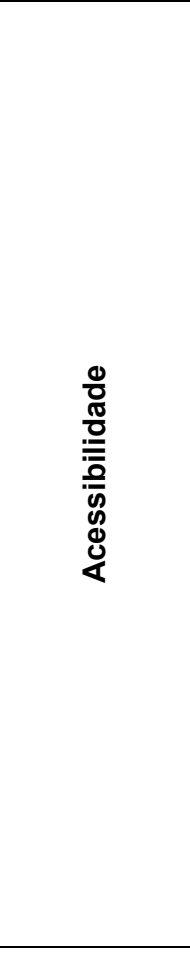 } & \multirow{7}{*}{$\begin{array}{c}\text { Sistemas que } \\
\text { permitem os } \\
\text { grupos de } \\
\text { indivíduos atinjam } \\
\text { atividades (ou } \\
\text { destinos) por meio } \\
\text { de transporte, e a } \\
\text { oferta de serviços }\end{array}$} & \multirow{7}{*}{$\begin{array}{l}\text { Stepniak } \\
\text { et al. } \\
(2019)\end{array}$} & \multirow{2}{*}{ Educação } & $\begin{array}{l}\text { Número de } \\
\text { escolas de } \\
\text { educação básica }\end{array}$ & $\begin{array}{l}\text { Secretária Municipal de } \\
\text { Educação de Belém - } \\
\text { SEMEC }\end{array}$ \\
\hline & & & & $\begin{array}{l}\text { Número de } \\
\text { escolas de nível } \\
\text { médio }\end{array}$ & $\begin{array}{l}\text { Secretária de Educação } \\
\text { do Estado do Pará - } \\
\text { SEDUC }\end{array}$ \\
\hline & & & \multirow{3}{*}{ Saúde } & $\begin{array}{l}\text { Número de postos } \\
\text { de atenção básica } \\
\text { (Nível primário) }\end{array}$ & \multirow{3}{*}{$\begin{array}{l}\text { Secretária Municipal de } \\
\text { Saúde de Belém - } \\
\text { SESMA } \\
\text { Secretária de Saúde do } \\
\text { Estado do Pará - SESPA }\end{array}$} \\
\hline & & & & $\begin{array}{l}\text { Número de } \\
\text { Unidades de } \\
\text { Pronto } \\
\text { Atendimento } \\
\text { (Nível secundário) }\end{array}$ & \\
\hline & & & & $\begin{array}{l}\text { Número de } \\
\text { Hospitais de Alta } \\
\text { complexidade } \\
\text { (Nível Terciário) }\end{array}$ & \\
\hline & & & \multirow{2}{*}{ Transporte } & $\begin{array}{l}\text { Disponibilidade e } \\
\text { frequência de } \\
\text { viagens de linhas } \\
\text { de ônibus }\end{array}$ & $\begin{array}{l}\text { Superintendência } \\
\text { Executiva de Mobilidade } \\
\text { Urbana de Belém - } \\
\text { SEMOB }\end{array}$ \\
\hline & & & & $\begin{array}{l}\text { Disponibilidade e } \\
\text { frequência de } \\
\text { viagens de linhas } \\
\text { de barcos }\end{array}$ & $\begin{array}{l}\text { Cooperativa de } \\
\text { Transportes Fluviais de } \\
\text { Belém - } \\
\text { COOTRANFLUBEL }\end{array}$ \\
\hline \multirow{2}{*}{ 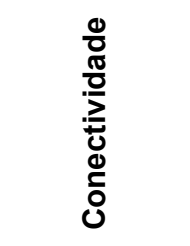 } & \multirow{2}{*}{$\begin{array}{l}\text { Processos } \\
\text { caracterizados por } \\
\text { fluxos globais e } \\
\text { tecnologias } \\
\text { conectadas via } \\
\text { redes de internet }\end{array}$} & \multirow{2}{*}{$\begin{array}{l}\text { Krieg } \\
(2018)\end{array}$} & Telefonia & $\begin{array}{l}\text { Número de } \\
\text { operadoras de } \\
\text { telefonia }\end{array}$ & \multirow{2}{*}{$\begin{array}{l}\text { Agência Nacional de } \\
\text { telecomunicações - } \\
\text { ANATEL }\end{array}$} \\
\hline & & & $\begin{array}{l}\text { Provedores } \\
\text { de Internet }\end{array}$ & $\begin{array}{l}\text { Número de } \\
\text { provedores de } \\
\text { internet }\end{array}$ & \\
\hline
\end{tabular}

O indicador de Acessibilidade a serviços se divide em três variáveis de análise onde:

a) A variável "Educação" no Brasil é classificada em dois níveis: I - Nível que compreende a educação infantil, ensino fundamental e o ensino médio; II - Nível que corresponde ao nível superior (BRASIL, 1996). Contudo, a variável de análise sobre a educação nas ilhas vai apenas focar no em nível 1, que abrange apenas o ensino básico.

b) A variável "Saúde" considera a formação da saúde pública no Brasil que divide o Sistema Único de Saúde (SUS) em três níveis de atenção. O nível primário realiza o atendimento inicial ou de casos mais simples; O nível secundário oferece atendimento especializado como as Unidades de Pronto Atendimento (UPA), ambulatórios e hospitais; e o nível terciário mais complexo, onde são classificados os grandes hospitais de tratamento de alta complexidade (BRASIL, 1990).

c) Para a variável "Transporte" define-se a partir a disponibilidade e a frequência de transportes coletivos oferecidos a partir de linhas de ônibus (ilhas que possuem pontes) e embarcações (ilhas que não possuem pontes) como meio de mobilidade de locomoção.

Para o indicador de Conectividade virtual as variáveis foram a:

a) A "telefonia" onde é formada a partir de dois tipos no Brasil: a telefonia móvel capaz de receber ou fazer chamadas em movimento e em qualquer lugar, onde tenha um sinal através de um aparelho portátil (celular) e a telefonia fixa é transmitida por meio de um aparelho a outro telefone ou a uma central de condução de sinal (BRASIL,1997).

b) A "internet" que se estrutura em vários níveis no Brasil: as linhas de conexão com maior fluxo de dados, que ligam os grandes centros de informação onde o fluxo é mais intenso; os pontos 
de conexão chamados Pontos de Troca de Tráfego (PTT); os Pontos de Presença, que são grandes centros de informação interligados; os Provedores responsáveis pela conexão dos usuários e as Infovias (rede de comunicação de dados) que conectam os usuários aos provedores de acesso (BRASIL, 2014).

O indicador de acessibilidade considera os vários tipos de acessos físicos existentes nas regiões insulares, agrupando os valores atribuídos aos indicadores segundo a importância estipulada do grau de isolamento (Tabelas 2 e 3 ).

Tabela 2 - Valores atribuídos a acessibilidade.

\begin{tabular}{|c|c|c|c|c|c|c|c|}
\hline \multirow{21}{*}{ 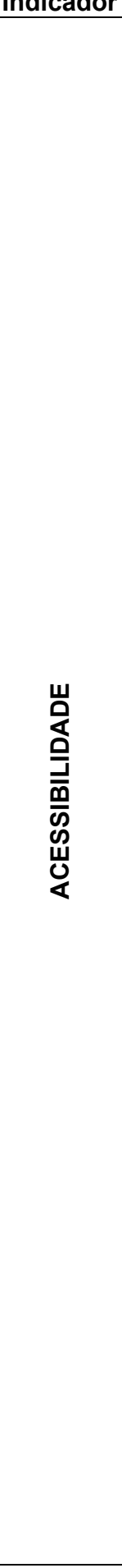 } & \multicolumn{3}{|l|}{ Variáveis } & \multicolumn{4}{|c|}{ Composição da variável } \\
\hline & \multirow{7}{*}{ Educação } & \multicolumn{2}{|c|}{ Escolas Ensino Infantil } & \multicolumn{2}{|c|}{$\begin{array}{l}\text { Escolas Ensino } \\
\text { Fundamental }\end{array}$} & \multicolumn{2}{|c|}{ Escolas Ensino Médio } \\
\hline & & $\mathrm{N}^{\circ}$ & $\begin{array}{l}\text { Valor } \\
\text { Atribuído }\end{array}$ & $\mathrm{N}^{\circ}$ & $\begin{array}{l}\text { Valor } \\
\text { Atribuído }\end{array}$ & $\mathrm{N}^{\circ}$ & $\begin{array}{l}\text { Valor } \\
\text { Atribuído }\end{array}$ \\
\hline & & 0 & 1 & 0 & 1 & 0 & 1 \\
\hline & & 1 a 4 & 2 & 1 a 4 & 2 & 1 a 4 & 2 \\
\hline & & 5 a 9 & 3 & 5 a 9 & 3 & 5 a 9 & 3 \\
\hline & & Mais de 10 & 4 & $\begin{array}{c}\text { Mais de } \\
10\end{array}$ & 4 & $\begin{array}{l}\text { Mais de } \\
10\end{array}$ & 4 \\
\hline & & \multicolumn{3}{|c|}{$\begin{array}{l}\text { Fórmula para soma dos valores da } \\
\text { composição da variável: } \\
\text { Escola Infantil + Escola Fundamental } \\
\text { + Escola Médio = Educação }\end{array}$} & \multicolumn{3}{|c|}{$\begin{array}{l}\text { Classificação do resultado da } \\
\text { variável: } \\
\text { Muito Baixo: } 3 \text { e } 4 \\
\text { Baixo: } 5 \text { e } 6 \\
\text { Moderado: } 7 \text { e } 8 \\
\text { Alto: } 9 \text { a } 12\end{array}$} \\
\hline & \multirow{8}{*}{ Saúde } & \multicolumn{6}{|c|}{ Composição da variável } \\
\hline & & \multicolumn{2}{|c|}{$\begin{array}{l}\text { Postos de Saúde - } \\
\text { Atendimento básico }\end{array}$} & \multicolumn{2}{|c|}{$\begin{array}{l}\text { UPA - Unidade de } \\
\text { Pronto Atendimento }\end{array}$} & \multicolumn{2}{|c|}{$\begin{array}{l}\text { Hospitais de alta } \\
\text { complexidade }\end{array}$} \\
\hline & & $\mathrm{N}^{\circ}$ & $\begin{array}{c}\text { Valor } \\
\text { Atribuído }\end{array}$ & $\mathrm{N}^{\circ}$ & $\begin{array}{c}\text { Valor } \\
\text { Atribuído }\end{array}$ & $\mathrm{N}^{\circ}$ & $\begin{array}{c}\text { Valor } \\
\text { Atribuído }\end{array}$ \\
\hline & & 0 & 1 & 0 & 1 & 0 & 1 \\
\hline & & 1 a 2 & 2 & 1 & 2 & 1 & 2 \\
\hline & & 3 a 5 & 3 & 2 & 3 & 2 & 3 \\
\hline & & Mais de 6 & 4 & 3 & 4 & 3 & 4 \\
\hline & & \multicolumn{3}{|c|}{$\begin{array}{l}\text { Fórmula para soma dos valores da } \\
\text { composição da variável: } \\
\text { Postos + UPA + Hospitais = Saúde }\end{array}$} & \multicolumn{3}{|c|}{$\begin{array}{l}\text { Classificação do resultado da } \\
\text { variável: } \\
\text { Muito Baixo: } 3 \text { e } 4 \\
\text { Baixo: } 5 \text { e } 6 \\
\text { Moderado: } 7 \text { e } 8 \\
\text { Alto: } 9 \text { a } 12\end{array}$} \\
\hline & \multirow{5}{*}{ Transporte } & \multicolumn{6}{|c|}{ Composição da variável } \\
\hline & & Via embarca & & Via ônibus & & $\begin{array}{l}\text { Tempo de } \\
\text { Saindo d } \\
\text { rodoviáric } \\
\text { Saindo d } \\
\text { Embarca }\end{array}$ & $\begin{array}{l}\text { lagem - } \\
\text { terminais } \\
\text { - Ônibus } \\
\text { Portos - } \\
\text { es }\end{array}$ \\
\hline & & $\begin{array}{l}\text { Frequência } \\
\text { de viagens } \\
\text { para Sede } \\
\text { Municipal }\end{array}$ & $\begin{array}{l}\text { Valor } \\
\text { Atribuído }\end{array}$ & $\begin{array}{l}\text { Frequência } \\
\text { de viagens } \\
\text { para Sede } \\
\text { Municipal }\end{array}$ & $\begin{array}{l}\text { Valor } \\
\text { Atribuído }\end{array}$ & $\begin{array}{l}\text { Duração } \\
\text { da } \\
\text { viagem }\end{array}$ & $\begin{array}{c}\text { Valor } \\
\text { Atribuído }\end{array}$ \\
\hline & & $\begin{array}{c}\text { Sem } \\
\text { transporte } \\
\text { coletivo }\end{array}$ & 1 & $\begin{array}{l}\text { Sem } \\
\text { transporte } \\
\text { coletivo }\end{array}$ & 1 & $\begin{array}{l}\text { Mais de } \\
180 \\
\text { minutos }\end{array}$ & 1 \\
\hline & & $\begin{array}{l}\text { Frequência } \\
\text { de } 3 \text { horas }\end{array}$ & 2 & $\begin{array}{l}\text { Frequência } \\
\text { de } 2 \text { horas }\end{array}$ & 2 & $\begin{array}{l}\text { Até } 120 \\
\text { minutos }\end{array}$ & 2 \\
\hline
\end{tabular}




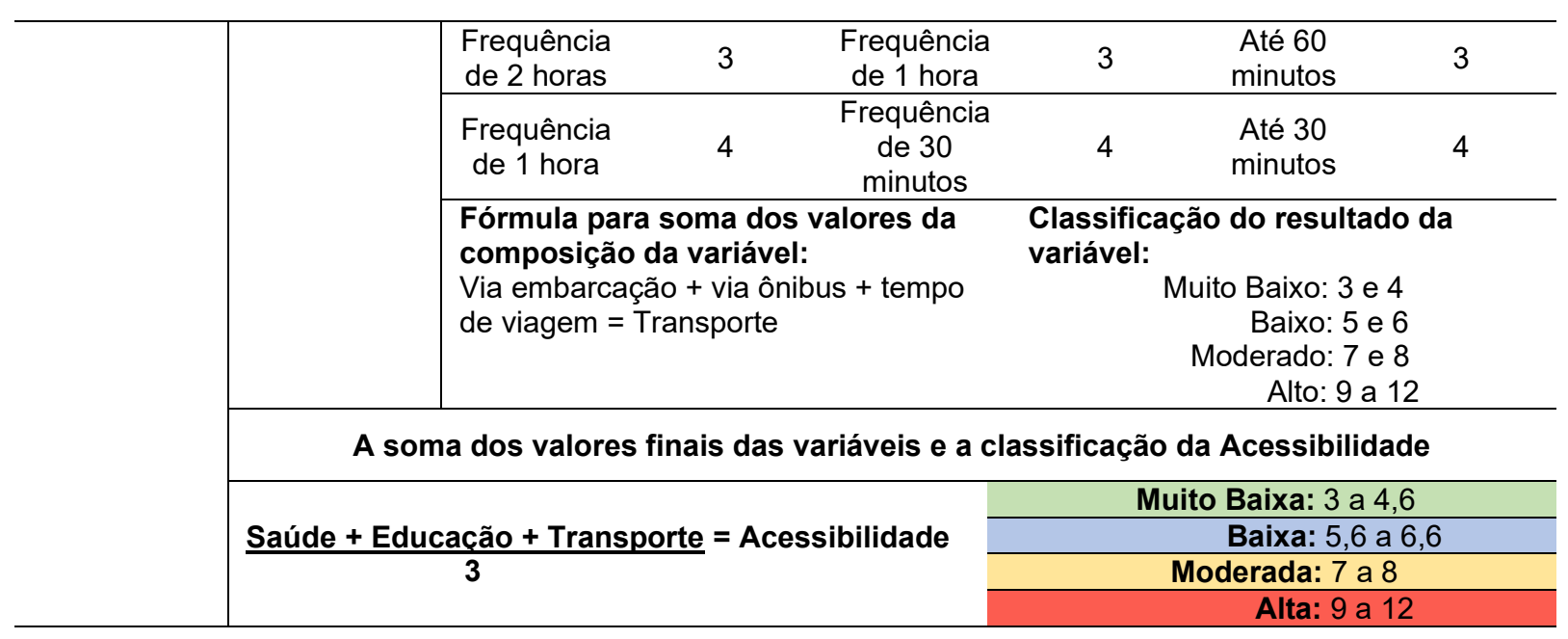

Fonte: Elaborado pelo autor.

O indicador da conectividade considera as fontes tecnológicas como facilitadores estratégicos para uma possível conexão não física, mas virtual onde a telefonia e provedores de internet estabelecem essa dinâmica (Tabela 3).

Tabela 3 - Valores atribuídos a conectividade.

\begin{tabular}{|c|c|c|c|}
\hline Indicador & \multicolumn{3}{|c|}{ Composição da variável } \\
\hline \multicolumn{4}{|c|}{ Operadoras de Telefonia } \\
\hline \multirow{15}{*}{ 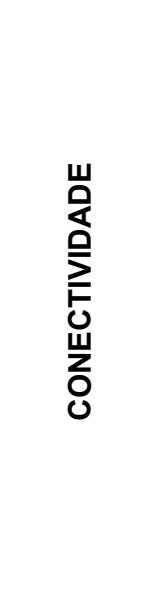 } & & $\mathrm{N}^{0}$ & Valores Atribuídos \\
\hline & & 0 & 1 \\
\hline & Teletonia & 1 & 2 \\
\hline & & 2 & 3 \\
\hline & & Mais de 3 & 4 \\
\hline & \multicolumn{3}{|c|}{ Número de provedores de internet } \\
\hline & \multirow{5}{*}{$\begin{array}{l}\text { Provedores } \\
\text { de Internet }\end{array}$} & $\mathrm{N}^{\circ}$ & Valores Atribuídos \\
\hline & & 0 & 1 \\
\hline & & 1 & 2 \\
\hline & & 2 & 3 \\
\hline & & Mais de 3 & 4 \\
\hline & \multicolumn{3}{|c|}{ A soma dos valores finais das variáveis e a classificação de Conectividade } \\
\hline & & & Muito baixa: 1 a 1,5 \\
\hline & Telefonia $+\mathrm{Pr}$ & ternet $=$ Conectividade & Baixa: 2 a 2,5 \\
\hline & & & Moderada: 3 a 3,5 \\
\hline
\end{tabular}

Fonte: Elaborado pelo autor.

Considerando os indicadores e seus respectivos valores atribuídos nas tabelas 2 e 3 a classificação dos valores finais destacada na tabela 4 segundo a condição de isolamento. 
Tabela 4 - Valores para estipular o grau de isolamento.

\begin{tabular}{lc}
\hline \multicolumn{2}{c}{ Média do índice do grau de Isolamento } \\
\hline Resultados & Classificação do Isolamento \\
\hline 6,3 a 7,8 & MUITO BAIXO \\
$\mathbf{4 , 8}$ a $\mathbf{5 , 5}$ & BAIXO \\
\hline $\mathbf{3 , 6}$ a $\mathbf{4 , 3}$ & MODERADO \\
\hline 2 a 2,8 & ALTO \\
\hline
\end{tabular}

Fonte: Elaborado pelo autor.

O grau de isolamento é compreendido através de uma escala baseada em valores de 2 a 7,8 onde 7,8 corresponde à máxima integração possível, e 2 corresponde ao máximo isolamento, e o valor entre 3,6 a 4,3 como o limite da condição de isolamento.

\section{RESULTADOS E DISCUSSÃO}

Os resultados obtidos para o indicador de acessibilidade (Tabela 5) definem acesso a serviços básicos como saúde, educação e transporte, considerando as condições de acessibilidade de cada ilha estudada no município de Belém. Os resultados apresentados na tabela classificam cada ilha de acordo com o nível de acessibilidade e indica os valores resultantes das variáveis.

Tabela 5 - Classificação da acessibilidade das ilhas segundo os valores atribuídos.

\begin{tabular}{|c|c|c|c|c|c|c|c|c|c|c|c|c|c|c|}
\hline \multirow{3}{*}{ Ilha } & \multicolumn{4}{|c|}{ SAÚDE } & \multicolumn{4}{|c|}{ EDUCAÇÃO } & \multicolumn{4}{|c|}{ TRANSPORTE } & \multirow{3}{*}{ 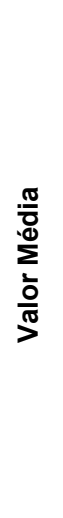 } & \multirow{3}{*}{ 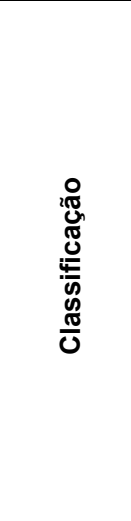 } \\
\hline & \multicolumn{3}{|c|}{$\begin{array}{l}\text { Valores } \\
\text { atribuídos a } \\
\text { unidades de } \\
\text { Saúde }\end{array}$} & \multirow{2}{*}{$\begin{array}{l}\frac{0}{0} \\
\frac{\pi}{5} \\
\frac{0}{9} \\
\mathbb{4}\end{array}$} & \multicolumn{3}{|c|}{$\begin{array}{c}\text { Valores atribuídos a } \\
\text { Escolas }\end{array}$} & \multirow{2}{*}{ 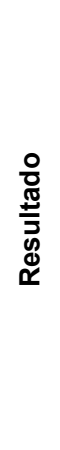 } & \multicolumn{2}{|c|}{$\begin{array}{c}\text { Valores } \\
\text { atribuídos } \\
\text { a } \\
\text { frequência } \\
\text { de saída } \\
\text { para sede } \\
\text { municipal }\end{array}$} & \multirow{2}{*}{ 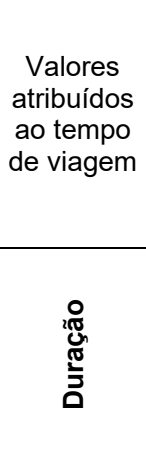 } & \multirow{2}{*}{ 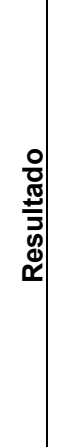 } & & \\
\hline & $\begin{array}{l}\text { o } \\
\text { के } \\
0 \\
0\end{array}$ & @ & $\begin{array}{l}\bar{\pi} \\
\frac{\pi}{0} \\
\text { 이 } \\
\text { 운 }\end{array}$ & & El & EF & EM & & 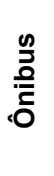 & 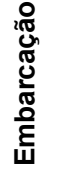 & & & & \\
\hline Mosqueiro & 3 & 1 & 2 & 6 & 4 & 3 & 3 & 10 & 4 & 1 & 2 & 7 & 7,6 & Moderada \\
\hline Outeiro & 3 & 1 & 1 & 5 & 3 & 2 & 2 & 7 & 4 & 1 & 3 & 8 & 6,6 & Baixa \\
\hline Cotijuba & 2 & 1 & 1 & 4 & 2 & 2 & 2 & 6 & 1 & 4 & 3 & 8 & 6 & Baixa \\
\hline Combú & 2 & 1 & 1 & 4 & 2 & 1 & 1 & 4 & 1 & 1 & 4 & 6 & 4,6 & $\begin{array}{l}\text { Muito } \\
\text { Baixa }\end{array}$ \\
\hline
\end{tabular}

UPA - Unidade de Pronto Atendimento; EI - Ensino Infantil; EF - Ensino Fundamental; EM- Ensino Médio.

Fonte: Elaborado pelo autor.

Os resultados da acessibilidade relacionada às ilhas de Belém estão diretamente ligados aos serviços ofertados à população. A ilha de Mosqueiro, embora localizada mais distante geograficamente da sede municipal, apresenta o melhor resultado no indicador acessibilidade, em função da maior disponibilidade de oferta de serviços. Verificou-se que a facilidade de acesso e o avanço do turismo desenvolveu os serviços na ilha ao longo dos anos. A ilha também apresenta uma forte autonomia de

$\begin{array}{lllll}\text { Caminhos de Geografia } \quad \text { Uberlândia-MG } & \text { v. 21, n. } 78 \quad \text { Dez/2020 } & \text { p. 325-342 Página } 334\end{array}$


desenvolvimento, de maneira que a oferta de determinados serviços não necessite o deslocamento dos ilhéus para a sede municipal. Mosqueiro também ainda conta com um transporte rodoviário regular, e que condiciona o fácil acesso para outras localidades, integrando assim a ilha ao continente.

A ilha de Outeiro apesar de possuir uma ponte rodoviária de conexão para sede municipal (o acesso rodoviário sendo um fator facilitador para a implementação de serviços), apresenta baixa eficiência de serviços básicos. A ilha mostra uma rede de saúde, transporte e educação regular, porém ainda indica uma forte dependência de serviços da sede municipal. A vantagem de possuir um eixo de ligação com Belém é um indicador para facilitar o desenvolvimento da ilha, contudo as estratégias de desenvolvimento ainda estão ligadas ao continente, o que leva a uma perda de autonomia insular.

Nas ilhas de Cotijuba e Combu, onde não há conexão pontes (acesso feito por linhas fluviais), pois sem acesso terrestre e a falta de políticas de desenvolvimento, as ilhas assumem uma autonomia administrativa própria de conduzirem as perspectivas de acesso a serviços básicos. Na ilha de Cotijuba conta com uma baixa acessibilidade, resultante dos serviços que são ineficientes na ilha, onde são buscados no distrito de Icoaraci-Belém (A 45 minutos para o continente). A ilha conta com uma linha regular de transporte fluvial, porém há 5 viagens diariamente para o continente, fato este que devido ao curto tempo de viagem, os serviços mais complexos são buscados fora ilha, onde observa-se que a acessibilidade a serviços na ilha ainda é limitada. A ilha de Combú obteve o pior resultado da análise da acessibilidade dentre as ilhas, apesar disso é a ilha mais próxima geograficamente da sede municipal, onde há presença de serviços básicos são escassos. Esse resultado se deve a uma acessibilidade de serviços dependente da cidade de Belém, por ser uma região insular próxima ao continente. A ilha não possui um cais e nem transporte coletivo com viagens fixas para a capital, o que se observa é um transporte individualizado, no qual cada ilhéu é responsável por sua mobilidade.

A conectividade analisada a partir das variáveis de desenvolvimento de tecnologias de telecomunicações pode reduzir as dimensões de comunicações, o que diminui as barreiras físicas de isolamento entre as ilhas e o continente. A conectividade é constituída das varáveis como os serviços de telefonia e internet, onde busca-se demonstrar que manter uma conexão virtual condiciona formas de integrar a região insular com o continente.

O indicador de conectividade em relação ao isolamento das ilhas destaca o número de operadoras de telefonia e o número de provedores de internet (Tabela 6). O indicador de conectividade é classificado pela média da soma dos resultados das variáveis analisadas em cada ilha.

Tabela 6 - Classificação da conectividade nas ilhas segundo os valores atribuídos.

\begin{tabular}{lcccc}
\hline Ilhas & $\begin{array}{l}\text { Valores atribuídos a } \\
\text { operadoras de } \\
\text { Telefonia }\end{array}$ & $\begin{array}{l}\text { Valores atribuídos } \\
\text { a provedores de } \\
\text { internet }\end{array}$ & Média & Classificação \\
\hline Mosqueiro & 4 & 3 & 3,5 & MODERADA \\
Outeiro & 4 & 2 & 3 & MODERADA \\
Cotijuba & 2 & 1 & 1,5 & MUITO BAIXA \\
Combu & 1 & 1 & 1 & MUITA BAIXA \\
\hline
\end{tabular}

Fonte: Elaborado pelo autor.

Os resultados melhores do indicador da conectividade estão diretamente relacionados com as ilhas que possuem conexão por pontes. Nesse sentido, percebe-se que as ilhas de Mosqueiro e Outeiro apresentaram resultados aproximados, e maiores ligações com a sede municipal, o que permitiu a expansão da conectividade nas ilhas, tanto na telefonia como a expansão de provedores de internet.

As ilhas de Cotijuba e Combú obtiveram índices de conectividade aproximados, pois a instalação de antenas de telecomunicações nas ilhas ainda é insuficiente, resultando em uma conectividade muito baixa $\mathrm{A}$ ilha de Cotijuba em relação a conectividade, ainda que precária, possui apenas um ponto fixo de telefonia na forma de antena de telecomunicação, o que favorece a comunicação na ilha. Em 
contrapartida, Combú não possui ponto fixo de telecomunicação, o que há de pontos comunicação isolados, que são instalações de antenas individualizadas, onde cada ilhéu e responsável aderir ou não a esse tipo de telecomunicação.

A classificação do grau de isolamento disposto em cada ilha analisada, se fundamenta nos resultados dos indicadores de acessibilidade e conectividade (Tabela 7). Desse modo, os indicadores se configuram como meios de tentar minimizar o isolamento geográfico de uma região insular.

Tabela 7 - Classificação do isolamento segundo a Acessibilidade e Conectividade.

\begin{tabular}{lcccc}
\hline \multicolumn{1}{c}{ Ilhas } & Acessibilidade & Conectividade & Média & Classificação \\
\hline Mosqueiro & 7,6 & 3,5 & 5,5 & BAIXO \\
Outeiro & 6,6 & 3 & 4,8 & BAIXO \\
Cotijuba & 6 & 1,5 & 3,7 & MODERADO \\
Combu & 4,6 & 1 & 2,8 & ALTO \\
\hline
\end{tabular}

Fonte: Elaborado pelo autor.

Os resultados especializados agregam os indicadores (acessibilidade e conectividade), onde se constatou que o grau do isolamento para a população que reside nas ilhas, não se relaciona com estar isolado geograficamente, mas pela dificuldade de acesso a serviços básicos, o que gera uma dependência de cidades próximas (Figura 4).

A ilha de Combú mostra um alto grau de isolamento mesmo mais próxima geograficamente da sede municipal (Belém-PA). As ilhas de Mosqueiro e Outeiro apresentaram níveis baixos de condições de isolamento, e Cotijuba apresenta nível moderado. O grau de isolamento classificado na ilha de Combú resulta da precária acessibilidade e conectividade, o que mostra a relação de dependência da sede municipal. A ilha do Combú possui características e aspectos de comunidades ribeirinhas, como a organização social, a ocupação e uso do território para subsistência, além do uso dos recursos naturais como condicionantes para a economia local. O Combú apresenta moradias em forma de palafitas localizadas nos leitos dos canais fluviais e na borda da ilha, sem acesso a saneamento básico, dificuldade de acesso a serviços de saúde, educação e com a economia proveniente do extrativismo e da pesca.

A acessibilidade de transportes na ilha do Combú se estrutura em um sistema de embarcações particulares de pequeno porte e sem cais central para transporte coletivo, configurando em uma acessibilidade individualizada. A conectividade relacionada a internet na ilha é inexistente, onde não há presença de serviços desse segmento. Conforme a análise baseada nos indicadores (acessibilidade e conectividade), observou-se que serviços ofertados na sede municipal (por proximidade física) impedem o desenvolvimento da ilha, logo deixando os ilhéus dependentes de serviços localizados no continente. A ilha do Combú exerce uma função importante de turismo no município de Belém, o que contribui com economia no município através de trilhas ao longo da ilha e a redes de restaurantes localizados as margens do rio Guamá e furo da Paciência (Figuras 6 e 7). A ilha do Combú exerce uma função importante do turismo no município de Belém, o que contribui com economia do turismo no município através de trilhas ao longo da ilha e a redes de restaurantes localizados as margens do rio Guamá e furo da Paciência. 
Figura 4 - Classificação do índice do grau de isolamento por ilha.

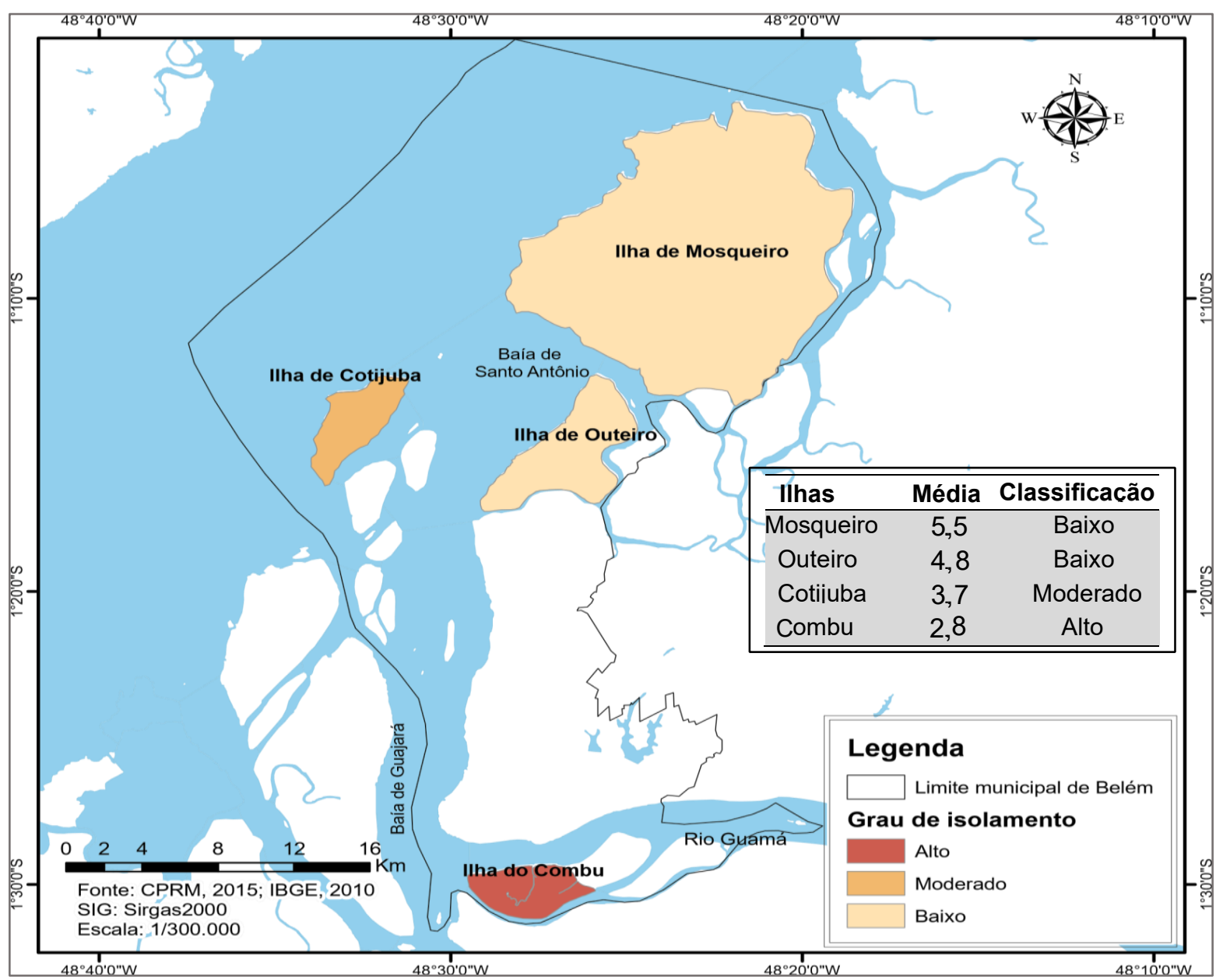

Fonte: Elaborado pelo autor.

Figura 6 - Furo do igarapé Combu.

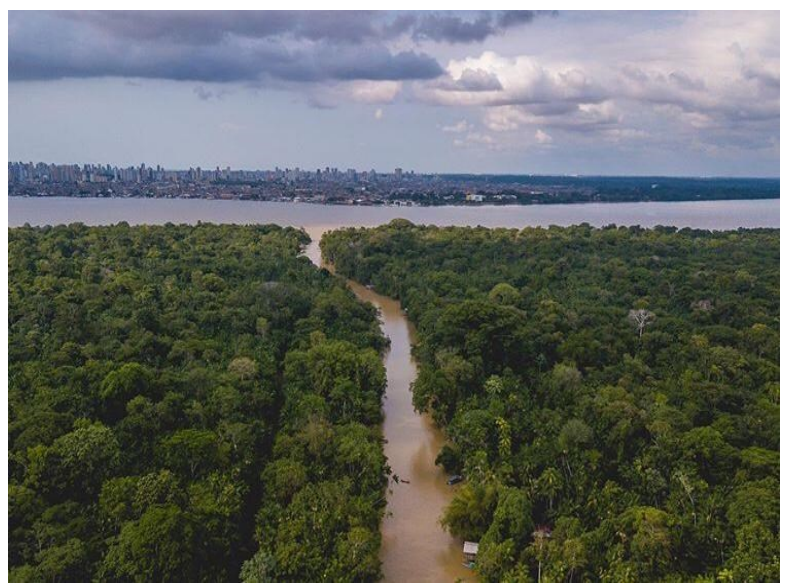

Figura 7 - Residências a margem do rio guamá.

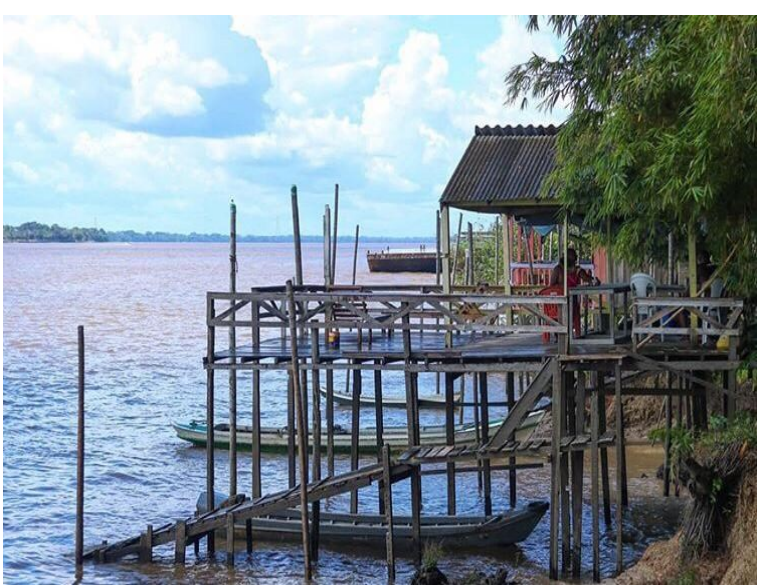

Fonte: Trabalhos de Campo, Junho, 2019. 
A ilha de Cotijuba (Figura 8) tem a relação com o continente instituída através do distrito administrativo de Icoaraci (Figura 9), onde se localiza o porto que recebe o transporte público hidroviário regular, única conexão de transporte disponível com a cidade de Belém. Nesse sentido, a ilha de Cotijuba apresenta um grau de isolamento moderado devido à relativa oferta de serviços e uma maior autonomia no desenvolvimento local, decorrente da "descoberta" da ilha para o turismo nos anos 2000, que necessitou de melhorias no transporte, comunicação e serviços. Os habitantes passaram a explorar prestações de serviços e demais atividades direcionadas ao atendimento de visitantes, o que modificou toda a dinâmica econômica da ilha.

Figura 8 - Porto da ilha de Cotijuba.

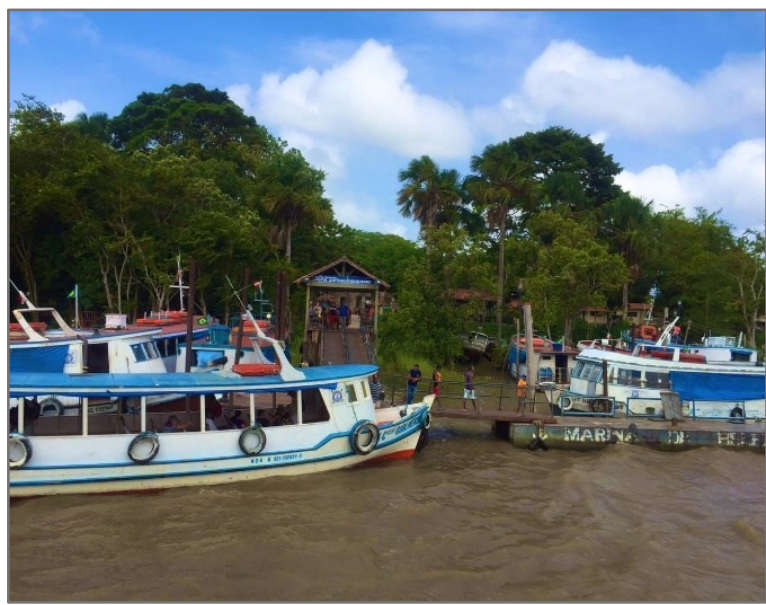

Figura 9 - Porto do distrito de icoaraci, principal ponto de conexão com a ilha de Cotijuba.

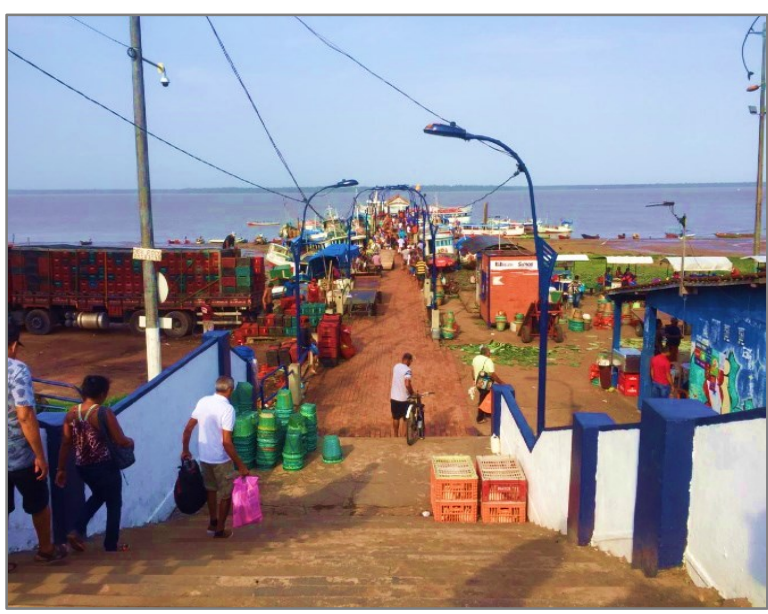

Fonte: Trabalhos de Campo, Agosto, 2019.

A ocupação em Cotijuba se diferenciou das demais ilhas analisadas, pois se estabeleceu no século XVIII através de um engenho de branqueamento de arroz e ponto de sinalização náutica. Durante anos os habitantes eram apenas agricultores, pescadores e ex-presidiários oriundos da casa penal. Contudo, a partir de 1930, com a intervenção do coronel Magalhães Barata foi construída uma escola técnica profissional (Educandário Nogueira de Farias), com função de receber a população infanto-juvenil da metrópole. Só a partir de 1985 a ocupação se intensificou com a doação de lotes pela a associação dos moradores da ilha, o que influenciou o aumento populacional (HÜFFNER, 2011).

A ilha de Caratateua-Outeiro (Figuras 10 e 11) demostrou um baixo grau de isolamento, devido ao seu processo histórico de ocupação, intensificado a partir da construção da ponte que liga a cidade de Belém, no qual caracterizou uma expansão urbana desordenada e irregular na ilha. A conexão pela ponte permitiu um relativo desenvolvimento da ilha, e o crescimento populacional, concentrando em sua maioria na parte oeste e sudoeste da ilha. Caratateua-Outeiro mesmo apresentando um regular desenvolvimento, perceber-se que ainda possui grande dependência de serviços da cidade de Belém, porém, é perceptível a falta de políticas públicas na ilha, o que diminui a perspectiva de desenvolvimento territorial.

A conexão pela ponte permitiu o desenvolvimento territorial da ilha de Outeiro, contudo, aumentou o crescimento populacional, concentrando em sua maioria na parte oeste e sudoeste da ilha. CaratateuaOuteiro mesmo apresentando um pequeno de desenvolvimento, perceber-se que a ilha ainda possui grande dependência de serviços da cidade de Belém. Contudo, é perceptível a falta de políticas públicas na ilha, o que diminui a perspectiva de desenvolvimento e crescimento econômico. 
Figura 10 - Ponte de acesso à llha de Outeiro.

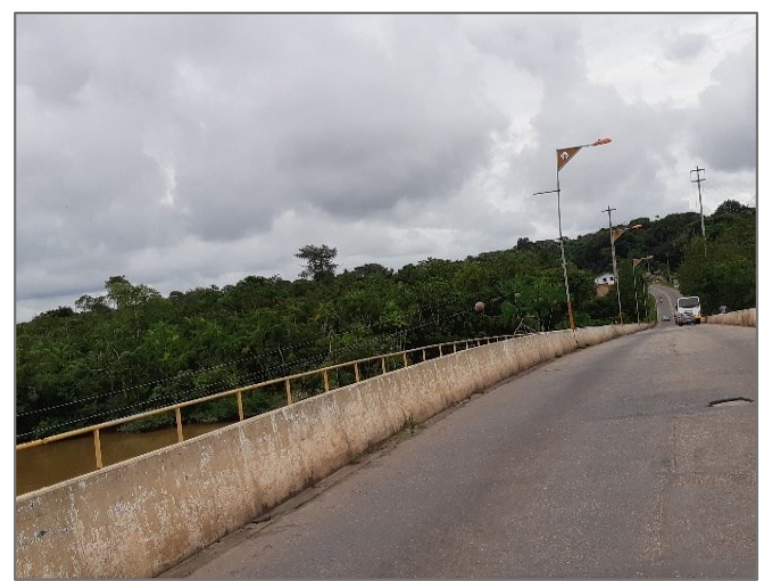

Figura 11 - Residências a margem da baia de Santo Antônio.

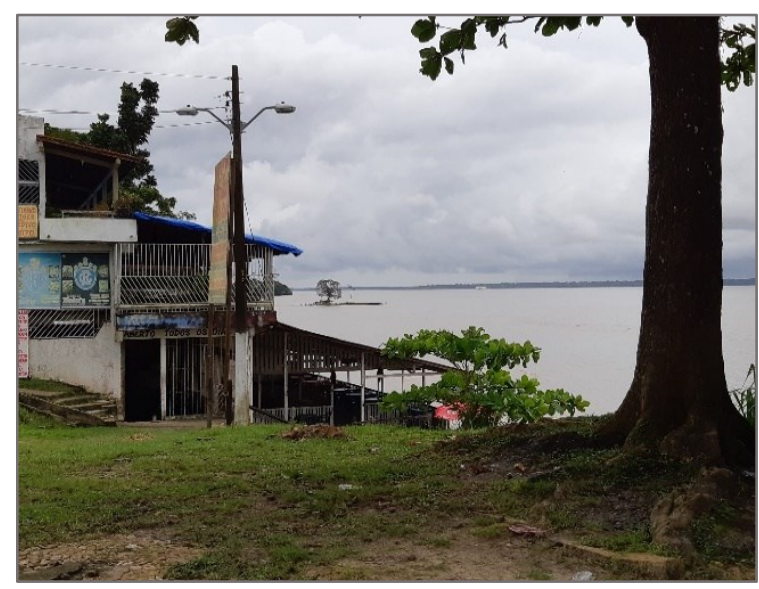

Fonte: Trabalhos de Campo, Agosto, 2019.

Somente a ilha de Mosqueiro (Figuras 12 e 13) apresentou um baixo nível de isolamento, devido à maior oferta de serviços, o que proporciona maior desenvolvimento e autonomia de gestão. $\mathrm{O}$ transporte rodoviário impulsionou o processo de integração da ilha aos demais municípios da região metropolitana de Belém, o que possibilitou maior mobilidade dos ilhéus.

Figura 12 - Orla principal da llha de Mosqueiro.

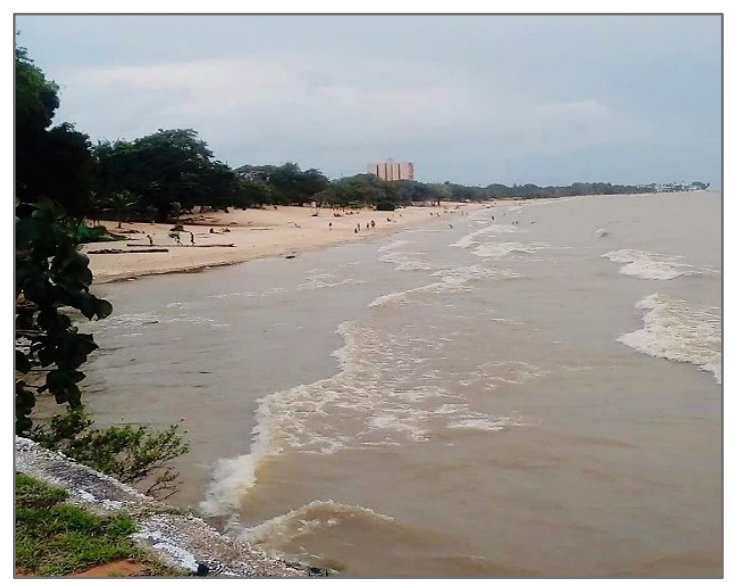

Figura 13 - Ponte de acesso a ilha.

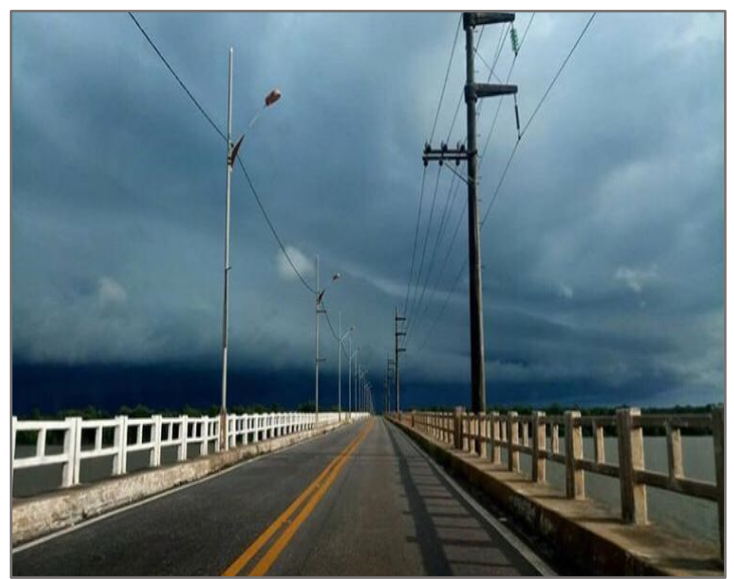

Fonte: Trabalhos de Campo, Julho, 2019.

A ilha de Mosqueiro tem suas especificidades atrelada há uma dinâmica do turismo, o que proporcionou uma ampla autonomia administrativa e um maior desenvolvimento insular em relação as outras ilhas, isso se atribuiu após a construção da ponte que liga a sede municipal, onde as possibilidades e formas de desenvolvimento aumentaram consideravelmente, culminando em uma expansão de serviços e telecomunicações. Nesse sentido, atualmente a ilha de Mosqueiro mostra uma dinâmica de urbanização caracterizada por residências sazonais (moradias em uma determinada época do ano) e residências permanentes localizadas ao norte e noroeste da ilha. 


\section{CONSIDERAÇÕES FINAIS}

Este artigo mostra a relação do isolamento e desenvolvimento nas ilhas de Belém-PA. Nesse sentido, percebe-se que nem sempre a distância geográfica da ilha para o continente define o estado de desenvolvimento insular, como por exemplo refletido em serviços básicos para a população, aqui analisados por indicadores como acessibilidade e conectividade.

Há situações em que ilhas mais próximas aos continentes são mais desenvolvidas, há outras, que por fatores específicos, tem seu desenvolvimento atrelado as sedes municipais. Desse modo, se verificou que as ilhas próximas ao continente têm desenvolvimento local escasso, uma vez que dependem da sede municipal. Residir em ilhas, mais precisamente na zona costeira amazônica, implica em algumas barreiras como o isolamento geográfico, e falta de acesso serviços básicos. Nesse sentido, o cenário do estudo a partir da análise multicritério, mostrou a ilha Mosqueiro com o menor grau de isolamento, e melhor desenvolvimento insular em relação as outras ilhas.

A acessibilidade aos serviços de saúde, educação e transporte e comunicação foi relevante para identificar os variados tipos de acesso, onde uma ilha pode não ser considerada isolada, mesmo distante fisicamente quando desenvolverem maiores serviços básicos aos ilhéus, assim superando a barreira física. A conectividade é um indicador que possibilita um novo tipo de acesso baseado em conexões por internet e telefonia, permitindo em grande medida às ilhas superem suas limitações físicas através da comunicação.

A metodologia de análise multicritério abarca as ilhas nas mais diferentes situações, tanto de localização quanto as características do desenvolvimento, o que resultou em diagnósticos distintos. No entanto, deve-se considerar não apenas a construção de ligações físicas como solução para diminuição do isolamento geográfico, mas todo tipo de acesso disponível. Também há que se considerar os fatores internos e externos em relação as ilhas, que desempenham funções importantes na definição do isolamento. Os fatores internos como taxa populacional, plano diretor e quantidade de serviços ofertados; e os fatores externos como plano de gestão insular, a insuficiência de políticas públicas adaptadas paras áreas insulares.

O papel do isolamento em relação do desenvolvimento de uma região insular se configura nas formas que impedem a conexão tanto física como virtual de se comunicar com outros territórios. Notou-se que as regiões insulares mais distantes do continente adquirem maior independência administrativa de gestão e relação as regiões próximas, porém não é uma regra geral, pois o isolamento é definido de acordo com características de cada região insular. Desta maneira, este método pode ser reproduzido não exclusivamente para ilhas na Amazônia, mas em outras regiões ou áreas em estado de isolamento.

\section{AGRADECIMENTOS}

Os autores agradecem a Coordenação de Aperfeiçoamento de Pessoal de Nível Superior - CAPES, por financiar a pesquisa, onde sem esse apoio nada disso seria possível.

\section{REFERÊNCIAS}

ANATEL. Agência Nacional de telecomunicações. Disponível em: <https://www.anatel.gov.br/institucional/> Acesso em: 10 dez. 2019.

BALDACCHINO, G. How far can one go? How distance matters in island development. Island Studies Journal, v.14, n. 1, 1-18, 2019. https://doi.org/10.24043/isj.70

BELLO. L.; HÜFFNER, J. Análise Dos Impactos Ambientais Da Expansão Urbana Na Ilha De Cotijuba, Belém-Pa. Revista Caminhos de Geografia, v. 13, n. 44, 286-298. 2012.

$B E T Z O L D, C$. Adapting to climate change in small island developing states. Climatic Change (133): 481-489: 2015. https://doi.org/10.1007/s10584-015-1408-0

BRASIL. LEI No 7.661 DE 16 DE MAIO DE 1988. Plano Nacional de Gerenciamento Costeiro, Brasília, DF, 1988. Disponível em: <http://www.planalto.gov.br/ccivil 03/Leis/L7661.htm>. Acesso em: 27 ago. 2019.

BRASIL. LEI N 8.080, DE 19 DE SETEMBRO DE 1990. Dispõe sobre as condições para a promoção da saúde e a organização e o funcionamento dos serviços correspondentes e dá outras providências. 
Brasília, DF, 1990. Disponível em: <http://www.planalto.gov.br/ccivil 03/leis/l8080.htm>. Acesso em: 09 set. 2019.

BRASIL. LEI No 9.394, DE 20 DE DEZEMBRO DE 1996. Lei de diretrizes e bases da educação nacional. Brasília, DF, 1996. Disponível em: <http://www.planalto.gov.br/ccivil 03/LEIS/L9394.htm>. Acesso em: 09 set. 2019.

BRASIL. LEI No 9.472, DE 16 DE JULHO DE 1997. Organização dos serviços de telecomunicações, criação e funcionamento de um órgão regulador. Brasília, DF, set. 1997. Disponível em: <http://www.planalto.gov.br/ccivil 03/LEIS/L9472.htm> Acesso em: 09 set. 2019.

BRASIL. LEI. No 12.965 DE 23 DE ABRIL DE 2014. Estrutura de internet no Brasil. Brasília, DF, 2014. Disponível em: < http://www.planalto.gov.br/ccivil 03/ ato2011-2014/2014/lei//12965.htm>. Acesso em: 09 set. 2019.

BRAZÃO e SILVA, S. Belém e o ambiente insular. Ed. 1, Belém: Editora EDUFRA, 165p. 2010.

CABRAL, E.; DIAS, J.; GOMES, S. Gestão Ambiental em Espaços de Lazer e Turismo: As Praias Urbanas da Amazônia Brasileira. Revista Rosa dos ventos - Turismo e hospitalidade, v. 7, n. 2: 1-19. 2015.

CABRAL, E.; DIAS, J.; GOMES, S. Gestão Ambiental em Espaços de Lazer e Turismo: As Praias Urbanas da Amazônia Brasileira. Revista Rosa dos ventos - Turismo e hospitalidade, v. 7, n. 2: 1-19. 2015.

CARVAJAL, L.; POCH, M.; OSÓRIO, R. Estudio Identificación de Localidades en Condiciones de Aislamiento. Subsecretaría de Desarrollo Regional y Administrativo - Departamento de Estudios y Evaluacion. Santiago, 242p. 2012.

CHAPERON, S; BRAMWELL, B. Dependency and agency in peripheral tourism development. Annals of Tourism Research, (40) 132-154: 2013. https://doi.org/10.1016/j.annals.2012.08.003

CODEM. Caracterização do território. Anuário Estatístico do Município de Belém. v. 17, Companhia Desenvolvimento e Administração da Área Metropolitana de Belém. Belém, 16p. 2012.

COOTRANFLUBEL. Cooperativa de Transportes Fluviais de Belém. Disponível em: $<$ http://paracooperativo.coop.br/sistema-ocb-pa/cooperativas> Acesso em: 10 dez. 2019.

CPRM. Serviço Geológico Brasileiro. Linhas de costa e ilhas. Acesso em 05 de fevereiro de 2015. Disponível em: http://www.cprm.gov.br

ESTADO DO PARÁ. LEI n 5.587 DE 09 DE MAIO DE 1995. Da política estadual do meio ambiente, Belém, PA. 1995. Disponível em: <https://www.semas.pa.gov.br/>. Acesso em: 15 jun. 2019

GOMES, L.; ARAYA, M; CARIGNANO, C. Tomada de Decisões em Cenários Complexos: introdução aos métodos discretos do apoio multicritério à decisão. Cengage Learning. São Paulo, 128p. 2011.

GRYDEHOJ, A. Critical approaches to island geography. Institute of Island Studies, University of Prince Edward Island:1-4. 2019. https://doi.org/10.1111/area.12546

GRYDEHOJ, A.; CASAGRANDE, M. Islands of connectivity: Archipelago relationality and transport infrastructure in Venice Lagoon. Area. 1-9: 2019. https://doi.org/10.1111/area.12529

GRYDEHOJ, A.; PINYA, X.; COOKE, G.; DORATL, N.; ELEWA, A.; KELMAN, I.; PUGH, J.; SCHICK, L.; SWAMINATHAN, R. Returning from the Horizon: Introducing Urban Island Studies. Urban Island Studies, v.1, n.1: 1-19: 2015. https://doi.org/10.20958/uis.2015.1

HUDSON, C.; DOOGAN N. The impact of geographic isolation on mental disability in the United States. Population Health (8): 1-10. 2019. https://doi.org/10.1016/j.ssmph.2019.100437

IBGE - Instituto Brasileiro de Geografia e Estatística. Bases territoriais. Rio de Janeiro: 2015. Disponível em: www.ibge.gov.br

IBGE - Instituto Brasileiro de Geografia e Estatística. Censo Demográfico. Rio de Janeiro: 2010. Disponível em: www.ibge.gov.br

IBGE - Instituto Brasileiro de Geografia e Estatística. Estimativas populacionais. Rio de Janeiro: 2010. Disponível em: www.ibge.gov.br 
KRIEG, L. Entangling (non)human isolation and connectivity: island nature conservation on lle aux Aigrettes, Mauritius. Island Studies Journal 13(2): 55-70. 2018. https://doi.org/10.24043/isj.68

MELÉNDEZ, O.; GONZÁLEZ, A. The implementation of the territorial development concept in the reality of virtual world: the case of Puerto Rico. International Conference Virtual City and Territory. Barcelona: Centre de Política de Sòl i Valoracions, (121) 1198-1208: 2016.

MIRANDA, L. Cidades, águas e ilhas no estuário amazônico. Labor e Engenho, v.9, n.2: 81-92. 2015. https://doi.org/10.20396/lobore.v9i2.8635579

NUNES, T. Mobilização local: ribeirinhos e a luta pela melhoria de vida na área insular de Belém/PA. Emblemas, v. 13 n. 1, p. 9-20, 2016.

PIKE, A; RODRÍGUEZ-POSE, A.; TOMANEY, J. What kind of local and regional development and for whom? In: IKE, A; RODRÍGUEZ-POSE, A.; TOMANEY, J. (Ed.): Local and Regional Development. Routlledge, (2). 18-56: 2017. https://doi.org/10.4324/9781315767673-2

PUGH, J. Relationality and island studies in the Anthropocene. Island Studies Journal, v.13, n.2, 93-110: 2018. https://doi.org/10.24043/isj.48

SEDUC. Secretária de Educação do Estado do Pará. Disponível em: <http://intranet.seduc.pa.gov.br/> Acesso em: 10 dez. 2019.

SEMEC. Secretária Municipal de Educação de Belém. Disponível em: <http://www.belem.pa.gov.br/semec/>. Acesso em: 10 dez. 2019.

SEMOB. Superintendência Executiva de Mobilidade Urbana de Belém. Disponível em: <http://www.belem.pa.gov.br/semob/site/> Acesso em: 10 dez. 2019.

SESMA. Secretária Municipal de Saúde de Belém. Disponível em: < www.belem.pa.gov.br/sesma/> Acesso em: 10 dez. 2019.

SESPA. Secretária de Saúde do Estado do Pará. Disponível em: <http://www.saude.pa.gov.br/> Acesso em: 10 dez. 2019.

STEPNIAK, M.; PRITCHARDB, J.; GEURSC, K.; GOLISZEKD, S. The impact of temporal resolution on public transport accessibility measurement: Review and case study in Poland. Journal of Transport Geography 75: 8-24. 2019. https://doi.org/10.1016/j.jtrangeo.2019.01.007

VIANA, I. Análise do processo de uso e ocupação da orla da praia do Areião (ilha de MosqueiroPA), tendo em vista o cumprimento das diretrizes do plano Nacional de gerenciamento costeiro (lei 7.661/88). Revista Geonorte, v. 8, n. 30, p. 63-77, 2017. https://doi.org/10.21170/geonorte.2017.V.8.N.30.63.77

ZAMORANO, F; SZLAFSZTEIN, C. Identificación del grado de aislamiento en territorios insulares: caso de estudio en la provincia de Chiloé (Chile). Cuadernos de Geografía: Revista Colombiana de Geografía. v. 29, n. 2, p. 427-439, 2020. Disponível em: <https://doi.org/10.15446/rcdg.v29n2.79755> Acesso em: 17 ago. 2020. https://doi.org/10.15446/rcdg.v29n2.79755

i Recebido em: 26/03/2020

Aceito para publicação em: 21/09/2020 